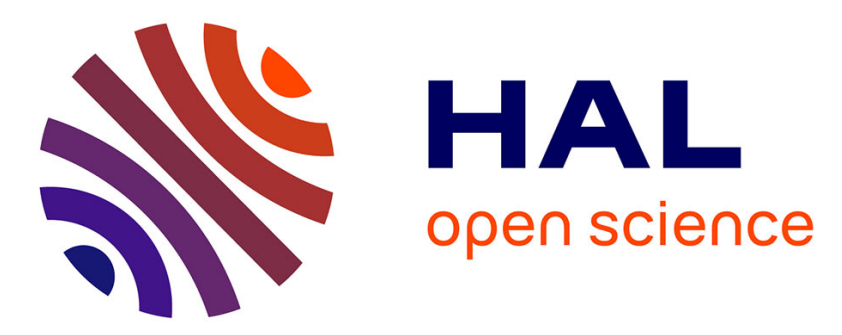

\title{
Neutron scattering study of the quasi-elastic spectral width in CeMg, CeMg 3 and NdMg3 intermetallic compounds
}

\author{
R.M. Galera, A.P. Murani, J. Pierre
}

\section{To cite this version:}

R.M. Galera, A.P. Murani, J. Pierre. Neutron scattering study of the quasi-elastic spectral width in CeMg, CeMg 3 and NdMg3 intermetallic compounds. Journal de Physique, 1985, 46 (2), pp.303-307. 10.1051/jphys:01985004602030300 . jpa-00209969

\section{HAL Id: jpa-00209969 https://hal.science/jpa-00209969}

Submitted on 1 Jan 1985

HAL is a multi-disciplinary open access archive for the deposit and dissemination of scientific research documents, whether they are published or not. The documents may come from teaching and research institutions in France or abroad, or from public or private research centers.
L'archive ouverte pluridisciplinaire HAL, est destinée au dépôt et à la diffusion de documents scientifiques de niveau recherche, publiés ou non, émanant des établissements d'enseignement et de recherche français ou étrangers, des laboratoires publics ou privés. 


\title{
Neutron scattering study of the quasi-elastic spectral width in $\mathrm{CeMg}, \mathrm{CeMg}_{3}$ and $\mathrm{NdMg}_{3}$ intermetallic compounds
}

\author{
R. M. Galera, A. P. Murani (*) and J. Pierre \\ Laboratoire Louis Néel, C.N.R.S., 166X, 38042 Grenoble Cedex, France \\ (*) Institut Laue-Langevin, 156X, 38042 Grenoble Cedex, France
}

(Reçu le 9 juillet 1984, révisé le 12 octobre, accepté le 23 octobre 1984)

\begin{abstract}
Résumé. - Des mesures de diffusion de neutrons ont été faites en vue d'étudier la partie quasi élastique du spectre magnétique dans les composés cubiques $\mathrm{CeMg}, \mathrm{CeMg}_{3}$ et $\mathrm{NdMg}_{3}$ ainsi que dans des composés dilués d'yttrium ou de lanthane. La largeur de raie quasi élastique a été mesurée jusqu'à $800 \mathrm{~K}$ dans $\mathrm{CeMg}_{3}$. A haute température elle suit une loi de Korringa qui intercepte l'origine à $T=0 \mathrm{~K}$, mais dévie au-dessous de $100 \mathrm{~K}$ et tend vers une valeur résiduelle $\gamma_{0}$ pour $T \rightarrow 0 \mathrm{~K}$. La valeur de $\gamma_{0}(\simeq 0,5 \mathrm{meV})$ est du même ordre de grandeur que dans CeMg $(\simeq 0,6 \mathrm{meV})$ et $\mathrm{NdMg}_{3}(\simeq 0,8 \mathrm{meV})$. Dans CeMg $\mathrm{Mg}_{3}$ et $\mathrm{NdMg}_{3}$, la largeur résiduelle décroît lorsqu'on dilue avec le lanthane ou l'yttrium alors que dans CeMg elle est très peu affectée par la dilution avec le lanthane et même augmente significativement dans le composé avec l'yttrium. Cette différence de comportement suggère une différence dans l'origine des mécanismes de relaxation dans les deux systèmes $\mathrm{CeMg}$ et $\mathrm{CeMg}_{3}$ à basse température.
\end{abstract}

\begin{abstract}
We report neutron scattering measurements of quasi-elastic magnetic spectra in cubic compounds $\mathrm{CeMg}, \mathrm{CeMg}_{3}$ and $\mathrm{NdMg}_{3}$ as well as in compounds diluted with $\mathrm{Y}$ and $\mathrm{La}$. The quasi-elastic linewidth measured up to $800 \mathrm{~K}$ in CeMg$g_{3}$ shows a linear Korringa law dependence at high temperature with a negligible intercept but deviates below $100 \mathrm{~K}$ and tends to a residual value $\gamma_{0}$ as $T \rightarrow 0 \mathrm{~K}$. The magnitude of $\gamma_{0}(\simeq 0.5 \mathrm{meV})$ is similar to that in $\mathrm{CeMg}(\simeq 0.6 \mathrm{meV})$ and $\mathrm{NdMg}_{3}(\simeq 0.8 \mathrm{meV})$. In $\mathrm{CeMg}_{3}$ and $\mathrm{NdMg}_{3}$ the residual linewidth decreases with dilution by $\mathrm{La}$ or $\mathrm{Y}$, whereas in CeMg the linewidth is only slightly affected on dilution with $\mathrm{La}$ and increases significantly on addition of $Y$. This difference in behaviour suggests different origins of the low temperature relaxation mechanisms in the two systems $\mathrm{CeMg}$ and $\mathrm{CeMg}_{3}$.
\end{abstract}

\section{Introduction.}

Pure cerium and some cerium intermetallic compounds are known to exhibit anomalous magnetic properties which have been classified as Kondo or intermediate valence behaviour [1, 2]. In recent years neutron scattering measurements have been reported on several of these systems, particularly measurements of the inelastic paramagnetic scattering which enable a determination of relaxation rates. In well-known intermediate valence systems $\mathrm{CePd}_{3}$ [3] and $\mathrm{CeSn}_{3}[4,5]$ a broad quasi-elastic spectrum of half width $\simeq 20-30 \mathrm{meV}$ was observed. More recent neutron inelastic scattering measurements on $\mathrm{CeSn}_{3}$ reveal, at low temperature, in addition to a weakly temperature dependent quasi-elastic scattering, a broad inelastic hump centred around $40 \mathrm{meV}$ which melts away into the quasi-elastic spectrum by around $130 \mathrm{~K}$ [6]. On the other hand the compounds like $\mathrm{CeAl}_{2}$ and $\mathrm{CeAl}_{3}$ [1], where the anomalies are very much smaller and the magnetic properties close to those of the trivalent ion, are considered as Kondo systems. In these systems neutron scattering measurements reveal inelastic peaks originating from crystal field levels as well as a central quasi-elastic mode whose linewidth increases roughly as $T^{1 / 2}$ from a residual value $\gamma_{0}=0.5 \mathrm{meV}$ at low temperatures [7,8]. The residual linewidth $\gamma_{0}$ is generally attributed to the Kondo coupling between the local moment and conduction electrons [1].

In this paper we report measurements of the spectral width of the quasi-elastic scattering performed on several cubic cerium compounds $\mathrm{CeMg}_{3}$ [9], $\mathrm{Ce}_{0.5} \mathrm{La}_{0.5} \mathrm{Mg}_{3}, \quad \mathrm{Ce}_{0.5} \mathrm{Y}_{0.5} \mathrm{Mg}_{3}, \quad \mathrm{CeMg}$ [10], $\mathrm{Ce}_{0.2} \mathrm{La}_{0.8} \mathrm{Mg}, \mathrm{Ce}_{0.2} \mathrm{Y}_{0.8} \mathrm{Mg}$ [11] as well as on neodymium compounds $\mathrm{NdMg}$ [12] and $\mathrm{Nd}_{0.5} \mathrm{La}_{0.5} \mathrm{Mg}_{3}$. We compare the behaviour of the quasi-elastic linewidth of compounds with different cerium or neodymium concentrations in order to understand the origin of spin relaxation in these systems. 


\section{Experimental.}

The measurements of the quasi-elastic paramagnetic scattering were performed on time-of-flight spectrometers IN4 and IN5 at the Institut Laue-Langevin. Two incident neutron energies were used in the experiments. $12.6 \mathrm{meV}$ neutrons were selected on the IN4 thermal beam spectrometer with overall elastic energy resolution $0.6 \mathrm{meV}$ (f. $\omega . \mathrm{h} . \mathrm{m}$ ). On the IN5 cold source spectrometer, neutrons of incident energy $3.5 \mathrm{meV}$ were used with an overall elastic energy resolution of $0.17 \mathrm{meV}$. The low temperatures (below $300 \mathrm{~K}$ ) were obtained by the use of ${ }^{4} \mathrm{He}$ cryostats and the higher temperatures $(300$ to $800 \mathrm{~K})$ by the use of a furnace. The time-of-flight spectra were normalized for detector efficiency with the help of the measured scattering from a standard vanadium sample and corrected for background scattering and self-shielding and the spectra are converted into $S(\theta, \omega)$, for constant scattering angle $\theta$.

\section{Results.}

The neutron scattering cross-section for an isotropic polycrystalline paramagnetic sample with crystal field split magnetic states can be expressed as :

$$
\begin{aligned}
& \frac{\mathrm{d}^{2} \sigma}{\mathrm{d} \Omega \mathrm{d} \omega}=\frac{N}{\left(g \mu_{\mathrm{B}}\right)^{2}}\left(\frac{\gamma e^{2}}{m_{\mathrm{e}} c^{2}}\right)^{2} \frac{k^{\prime}}{k}\left[\frac{1}{2} g f(Q)\right]^{2} \times \\
& \quad \times \frac{\omega}{1-\mathrm{e}^{-\omega \beta}}\left[a_{0} F_{Q}^{0}(\omega)+\sum_{\alpha=1}^{n} a_{\alpha} F_{Q}^{\alpha}\left(\omega \pm \omega_{\alpha}\right)\right]
\end{aligned}
$$

where $a_{0}, a_{\alpha}(\alpha=1, n)$ represent the normalized temperature dependent probability factors and $F_{Q}^{0}(\omega)$, $F_{Q}^{\alpha}\left(\omega \pm \omega_{\alpha}\right)(\alpha=1, n)$ the spectral weight functions of respectively the quasi-elastic and inelastic peaks.
In figure 1, we show the spectra for $\mathrm{Ce}_{0.2} \mathrm{Y}_{0.8} \mathrm{Mg}$ for one scattering angle measured with the low incident energy neutrons $(3.5 \mathrm{meV})$. The solid lines in the figure are the results of fits to the quasi-elastic spectrum in the energy range $-2 \leqslant \omega \leqslant 2 \mathrm{meV}$. In this energy range no phonon branches are cut, because of the low incident energy, hence the phonon contribution is negligible as also verified by measurements on $\mathrm{YMg}$ and $\mathrm{LaMg}_{3}$. Also the crystal field inelastic excitations occur at relatively high energy $\left(\Delta_{\mathrm{CEF}}=16 \mathrm{meV}\right.$ in $\mathrm{CeMg}$ [10] and $10.6 \mathrm{meV}$ in $\mathrm{NdMg}_{3}$ [12]) and do not contribute in this energy range. For all spectra in this work we have used a Lorentzian form for $F_{Q}^{0}(\omega)$. In figure 2, we plot the temperature dependence of the quasi-elastic spectral component for $\mathrm{CeMg}$, $\mathrm{Ce}_{0.2} \mathrm{La}_{0.8} \mathrm{Mg}$ and $\mathrm{Ce}_{0.2} \mathrm{Y}_{0.8} \mathrm{Mg}$. For all three compounds in the studied temperature range, the quasielastic linewidth varies linearly with the temperature and tends to a residual value $\gamma_{0}$ as $T \rightarrow 0 \mathrm{~K}: \gamma_{0} \simeq$ $0.6 \mathrm{meV}$ for $\mathrm{CeMg}, 0.5 \mathrm{meV}$ for $\mathrm{Ce}_{0.2} \mathrm{La}_{0.8} \mathrm{Mg}$ and $1.1 \mathrm{meV}$ for $\mathrm{Ce}_{0.2} \mathrm{Y}_{0.8} \mathrm{Mg}$. For $\mathrm{CeMg}_{3}$ (Fig. 3) the quasi-elastic linewidth $\gamma$ was measured over a large temperature range (from 8 to $800 \mathrm{~K}$ ). Above $100 \mathrm{~K}, \gamma$ increases linearly with temperature. Below $100 \mathrm{~K}$, $\gamma$ deviates from the linear dependence and tends to a finite value of $\gamma_{0} \simeq 0.5 \mathrm{meV}$ as $T \rightarrow 0 \mathrm{~K}$. In figure 4 we present the results for $\mathrm{CeMg}_{3}, \mathrm{Ce}_{0.5} \mathrm{La}_{0.5} \mathrm{Mg}_{3}$ and $\mathrm{Ce}_{0.5} \mathrm{Y}_{0.5} \mathrm{Mg}_{3}$ at low temperature. The quasielastic linewidth of $\mathrm{Ce}_{0.5} \mathrm{La}_{0.5} \mathrm{Mg}_{3}$ and $\mathrm{Ce}_{0.5} \mathrm{Y}_{0.5} \mathrm{Mg}_{3}$ tends to a residual value, as $T \rightarrow 0 \mathrm{~K}$, but has a magnitude smaller than that of $\mathrm{CeMg}_{3}: \gamma_{0} \simeq 0.3 \mathrm{meV}$ and $0.2 \mathrm{meV}$ respectively for $\mathrm{Ce}_{0.5} \mathrm{La}_{0.5} \mathrm{Mg}_{3}$ and $\mathrm{Ce}_{0.5} \mathrm{Y}_{0.5} \mathrm{Mg}_{3}$. Finally, in figure 5 we show the quasi-elastic linewidth for $\mathrm{NdMg}_{3}$ and $\mathrm{Nd}_{0.5} \mathrm{La}_{0.5} \mathrm{Mg}_{3}$ up to $250 \mathrm{~K}$ and $80 \mathrm{~K}$ respectively. The quasi-elastic linewidth of $\mathrm{NdMg}_{3}$ increases linearly with tempera-
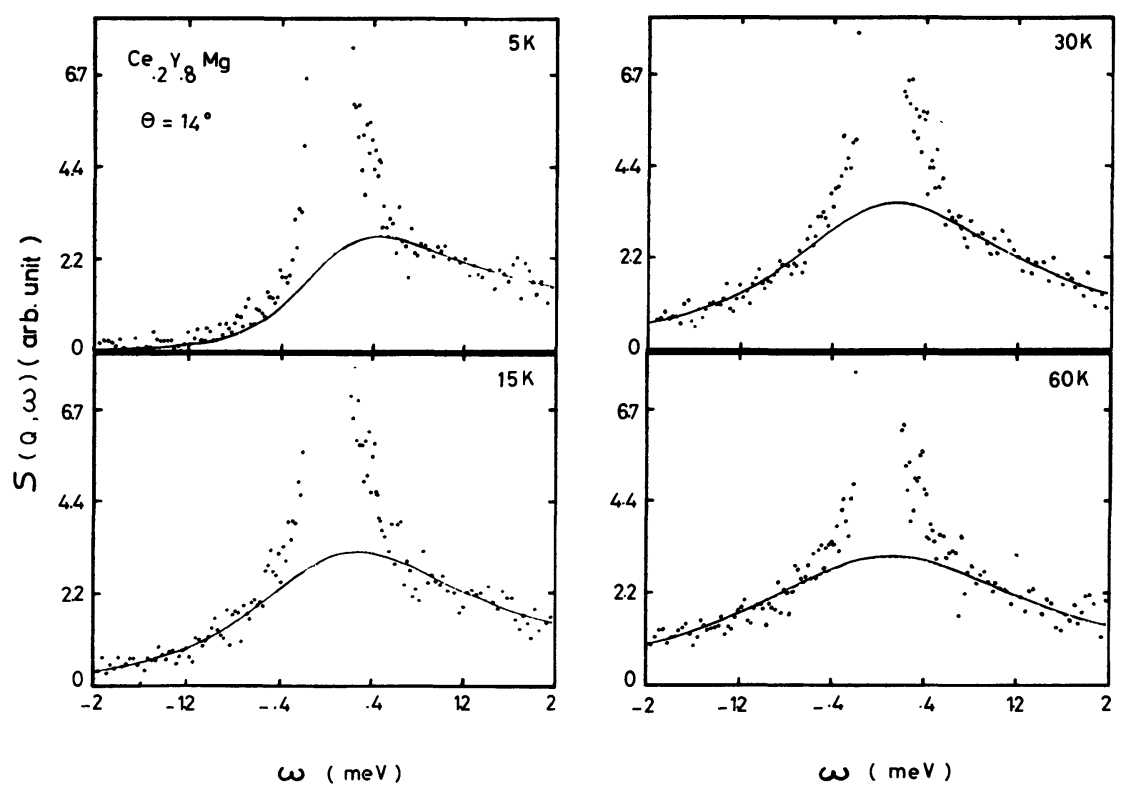

Fig. 1. $-S(\theta, \omega)$ for one scattering angle for $\mathrm{Ce}_{0.2} \mathrm{Y}_{0.8} \mathrm{Mg}$ at different temperatures over the energy range $-2 \leqslant \omega \leqslant 2 \mathrm{meV}$. The continuous curves represent fits to the data using a Lorentzian as quasi-elastic spectral function. 


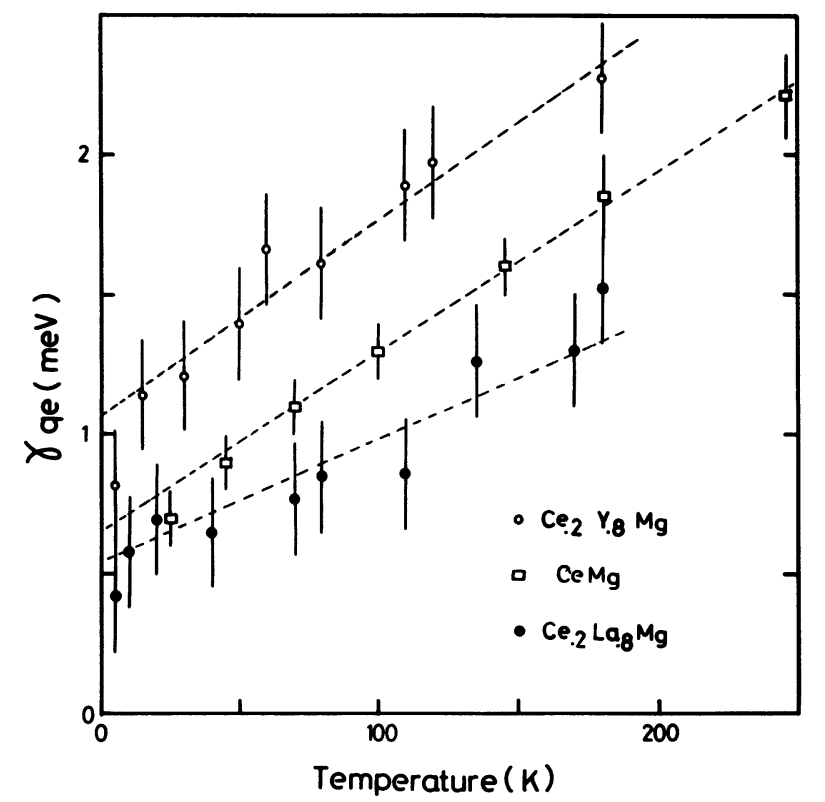

Fig. 2. - Variation of the quasi-elastic linewidth $\gamma$ (halfwidth at half-height) versus temperature for $\mathrm{CeMg}$. $\mathrm{Ce}_{0.2} \mathrm{Y}_{0.8} \mathrm{Mg}$ and $\mathrm{Ce}_{0.2} \mathrm{La}_{0.8} \mathrm{Mg}$. The dashed lines are guides for the eye.

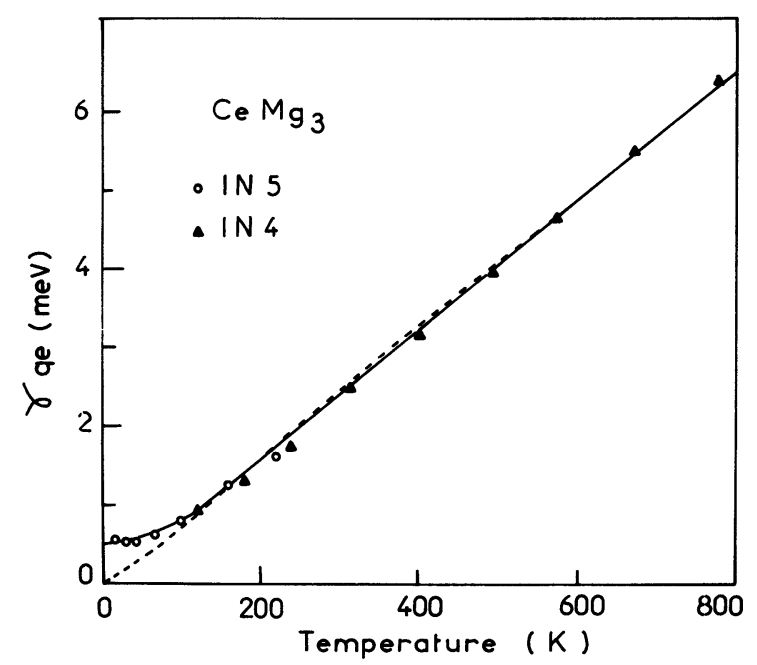

Fig. 3. - Variation of the quasi-elastic linewidth $\gamma$ for $\mathrm{CeMg}_{3}$ over the temperature range $8-800 \mathrm{~K}$. The dashed line represents the fit to the data using the theory of Becker et al. [13].

ture from a value $\gamma_{0} \simeq 0.8 \mathrm{meV}$ as $T \rightarrow 0 \mathrm{~K}$. In $\mathrm{Nd}_{0.5} \mathrm{La}_{0.5} \mathrm{Mg}_{3}$ the quasi-elastic linewidth is not as broad as in $\mathrm{NdMg}_{3}$ and has the value $\gamma_{0} \simeq 0.5 \mathrm{meV}$.

\section{Discussion.}

The variation of the quasi-elastic linewidth in $\mathrm{CeMg}_{3}$ was in a first approach fitted by the theory of Becker et al. [13] for the relaxation of crystal field excitations in metallic rare-earth systems. This calculation was performed for the classical s-f exchange Hamiltonian.

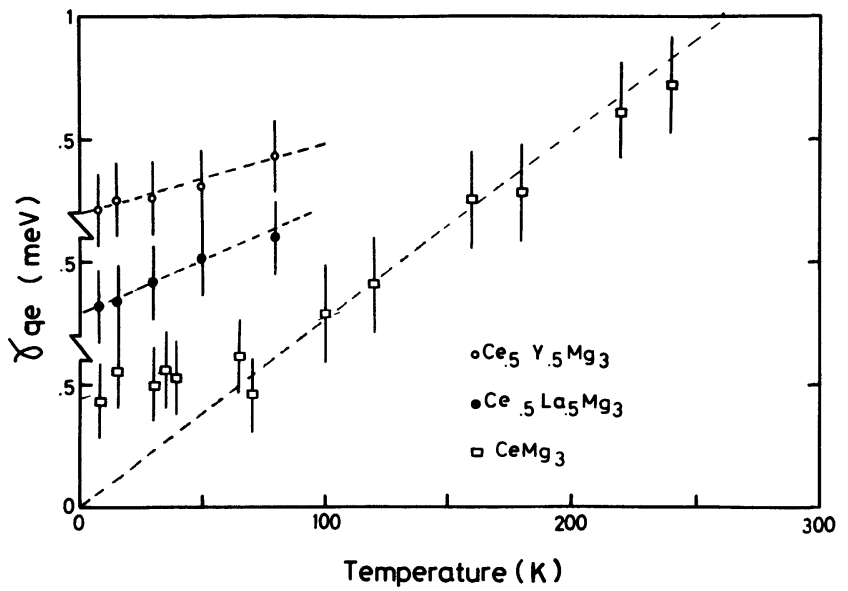

Fig. 4. - Low temperature dependence of the quasi-elastic linewidth $\gamma$ in $\mathrm{CeMg}_{3}, \mathrm{Ce}_{0.5} \mathrm{Y}_{0.5} \mathrm{Mg}_{3}$ and $\mathrm{Ce}_{0.5} \mathrm{La}_{0.5} \mathrm{Mg}_{3}$. The dashed lines are drawn to guide the eye.

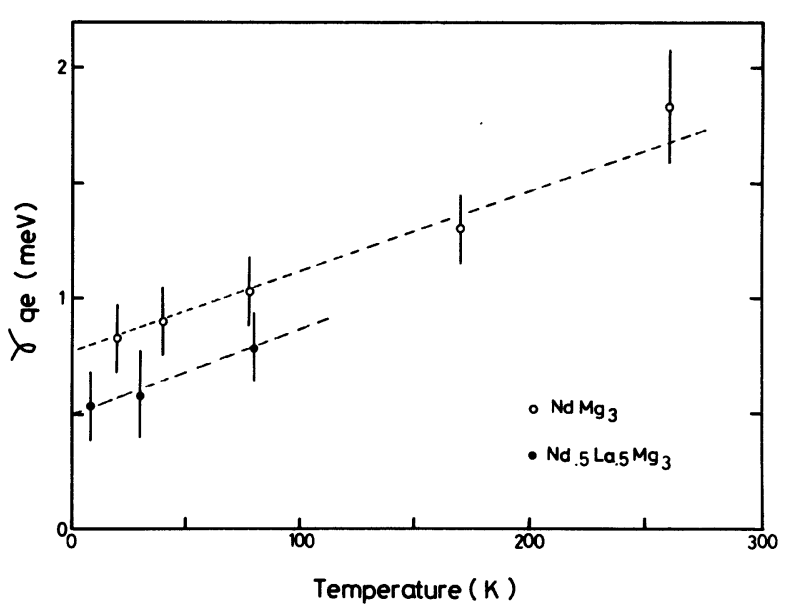

Fig. 5. - Temperature variation of the quasi-elastic linewidth for the neodymium compounds $\mathrm{NdMg}_{3}$ and $\mathrm{Nd}_{0.5} \mathrm{La}_{0.5} \mathrm{Mg}_{3}$. Dashed lines are guides for the eye.

The best fit was obtained with $\left|J n\left(E_{\mathrm{F}}\right)\right| \simeq 0.3$, where $J$ is the exchange constant. However, this value was not in agreement with the value deduced from resistivity [15] $\left(\operatorname{Jn}\left(E_{\mathrm{F}}\right) \simeq-0.04\right)$ and was too high for a compound where the Kondo coupling is rather weak, as we shall see in the following.

Lopes and Coqblin [14] have, in a recent work, calculated the relaxation of crystal field excitations using the Coqblin-Schrieffer Hamiltonian. The $J=5 / 2$ multiplet of the cerium ion is split by the cubic symmetry into a doublet $\Gamma_{7}$ and a quadruplet $\Gamma_{8}$. For $T \gg \Delta$ the neutron quasi-elastic spectrum is the sum of two quasi-elastic lines corresponding to the transitions within respectively $\Gamma_{7}$ and $\Gamma_{8}$. The quasi-elastic linewidth is expressed as :

$$
\begin{aligned}
& \gamma_{q e}\left(\Gamma_{7}\right)=4 \Pi\left|n\left(E_{\mathrm{F}}\right)\right|^{2}\left[\left|J_{77}\right|^{2}+2\left|J_{78}\right|^{2}[T\right. \\
& \left.\left.\gamma_{q e}\left(\Gamma_{8}\right)=4 \Pi\left|n\left(E_{\mathrm{F}}\right)\right|^{2}\right] 2\left|J_{88}\right|^{2}+\left|J_{78}\right|^{2}\right] T .
\end{aligned}
$$


These expressions have the same form as the corresponding expressions of Becker et al., except that they involve the $\left|J_{\mathbf{M M}^{\prime}}\right|^{2}$ values instead of $|(g-1) J|^{2}$.

In our experiments above $300 \mathrm{~K}(T \gg \Delta, \Delta=$ $197 \mathrm{~K})$ the transitions within the $\Gamma_{8}$ are the main contributions in the quasi-elastic linewidth. From the high temperature slope we deduce $\mid n\left(E_{\mathrm{F}}\right)\left(2\left|J_{\mathbf{8 8}}\right|^{2}+\right.$ $\left.+\left|J_{78}\right|^{2}\right)\left.\right|^{1 / 2} \simeq 0.08$, value which is in much better agreement with the resistivity data.

In a first analysis the residual value $\gamma_{0}$ of the quasielastic linewidth in $\mathrm{CeMg}_{3}$ and in $\mathrm{CeMg}$ can be attributed to the Kondo coupling between the local moment and conduction electrons. However, the results on the dilute compounds and on $\mathrm{NdMg}_{3}$ (Fig. 5) show that the Kondo coupling is not the only possible mechanism for the residual linewidth. In fact, since $\mathrm{NdMg}_{3}$ is not a Kondo system, the residual linewidth in this case can only be due to the exchange coupling of the R.K.K.Y. type. In such systems the dilution by non-magnetic ions (lanthanum or yttrium) should reduce the interactions and hence the residual width. This is verified by measurements on $\mathrm{Nd}_{0.5} \mathrm{La}_{0.5} \mathrm{Mg}_{3}$ (Fig. 5). Similarly, the reduction of the quasi-elastic linewidth observed in dilute compounds $\mathrm{Ce}_{0.5} \mathrm{La}_{0.5} \mathrm{Mg}_{3}$ and $\mathrm{Ce}_{0.5} \mathrm{Y}_{0.5} \mathrm{Mg}_{3}$ (Fig. 4) implies that the relaxation in $\mathrm{CeMg}_{3}$ is mainly due to the exchange coupling. In this connection, we recall that the specific heat of both $\mathrm{CeMg}_{3}$ and $\mathrm{NdMg}$ has a long tail above the $\lambda$-type anomaly at the Néel temperature, at 4 and $6 \mathrm{~K}$ respectively, and the magnetic entropy up to $T_{\mathrm{N}}$ is lower than $R \ln 2$, which is the value for a ground state doublet $\Gamma_{7}$ in $\mathrm{CeMg}_{3}$ [15] and $\Gamma_{6}$ in $\mathrm{NdMg}_{3}$ [15]. This may be understood as suggesting the existence of magnetic correlations above $T_{\mathrm{N}}$ in these compounds.

The measurements on $\mathrm{CeMg}$ have not been made up to sufficiently high temperatures to enable any conclusions about the relaxation behaviour at high temperature to be drawn, for example the Korringa law as in $\mathrm{CeMg}_{3}$, or $\mathrm{T}^{1 / 2}$ variation as in $\mathrm{CeAl}_{2}$ [7] or $\mathrm{CeAl}_{3}$ [8]. However, at low temperatures the behaviour of the quasi-elastic linewidth in $\mathrm{CeMg}$, $\mathrm{Ce}_{0.2} \mathrm{La}_{0.8} \mathrm{Mg}$ and $\mathrm{Ce}_{0.2} \mathrm{Y}_{0.8} \mathrm{Mg}$ is different from that of $\mathrm{CeMg}_{3}, \mathrm{Ce}_{0.5} \mathrm{La}_{0.5} \mathrm{Mg}_{3}$ and $\mathrm{Ce}_{0.5} \mathrm{Y}_{0.5} \mathrm{Mg}_{3}$, in that the linewidth does not decrease with dilution. Previous magnetization measurements on $\mathrm{CeMg}$ under pressure have revealed a linear decrease of the Néel temperature with increasing pressure [16], and the relative variation of $\mathrm{d}\left(\ln T_{\mathrm{N}}\right) / \mathrm{d} p$ is comparable to that found in $\mathrm{CeAl}_{2}$ [17]. These results are in agreement with the theory of Doniach [18] and Lavagna et al. [19] for dense Kondo systems. Thus, CeMg appears similar to the Kondo system $\mathrm{CeAl}_{2}$. Returning to the effect of dilution, we note that dilution of $\mathrm{CeMg}$ by lanthanum does not significantly change the residual quasi-elastic linewidth $\left(\gamma_{0} \simeq 0.5 \mathrm{meV}\right.$ in $\mathrm{Ce}_{0.2} \mathrm{La}_{0.8} \mathrm{Mg}$ and $\simeq$ $0.6 \mathrm{meV}$ in $\mathrm{CeMg}$ ). However, dilution with yttrium enhances the residual width $\left(\gamma_{0} \simeq 1.1 \mathrm{meV}\right.$ in $\mathrm{Ce}_{0.2} \mathrm{Y}_{0.8} \mathrm{Mg}$ ). This is because the Kondo coupling is enhanced by the chemical pressure due to the addition of yttrium (YMg has a smaller lattice constant than $\mathrm{CeMg}$ ). This is also seen from electrical resistivity measurements in $\mathrm{Ce}_{0.2} \mathrm{Y}_{0.8} \mathrm{Mg}$ where a minimum is observed [11]. Similar results have been obtained on $\mathrm{Ce}(\mathrm{La}, \mathrm{Y}) \mathrm{Al}_{2}$ systems by Steglich and Loewenhaupt [20]. All these results are also in agreement with the increase of the quasi-elastic linewidth of CeAg under external pressure [21].

It may, at first sight, appear surprising that the residual linewidth in $\mathrm{CeMg}_{3}\left(T_{\mathrm{N}}=4 \mathrm{~K}\right)$ is dominated by ion-ion exchange interactions, whereas in $\mathrm{CeMg}$ the origin of the residual width is mainly through Kondo coupling, although in the latter compound the ordering temperature is much higher $\left(T_{\mathrm{N}}=19 \mathrm{~K}\right)$. As noted above, the specific heats of $\mathrm{CeMg}_{3}$ and $\mathrm{NdMg}_{3}$ show a large tail above $T_{\mathrm{N}}$ suggesting persistence of magnetic correlations to relatively high temperatures. The magnetic order in $\mathrm{CeMg}$ on the contrary occurs as a first-order phase transition driven principally by magneto-elastic interactions and shows little or no precursory effects in susceptibility or specific heat measurements [10]. Hence, the exchange interactions do not have the same influence in $\mathrm{CeMg}$ as in $\mathrm{CeMg}_{3}$. In other words, the relative magnitudes of the ordering temperatures in $\mathrm{CeMg}$ and $\mathrm{CeMg}_{3}$ is not a good indicator of the relative effect of the exchange coupling on the low temperature residual width in the two systems. Finally, the higher concentration of $\mathrm{Ce}$ in $\mathrm{CeMg}$ relative to $\mathrm{CeMg}_{3}$ may also naively lead us to expect stronger interaction effects in the former than in the latter compound. However, such an argument clearly breaks down when carried over to the case of pure Ce.

\section{Conclusions.}

We have measured the quasi-elastic linewidth in cubic $\mathrm{CeMg}, \mathrm{CeMg}_{3}$ and $\mathrm{NdMg}_{3}$ compounds, as well as in their diluted compounds. In $\mathrm{CeMg}_{3}$, measurements up to high temperature have shown a linear Korringa law behaviour with zero intercept, except below $100 \mathrm{~K}$ where we observe deviations giving a residual width as $T \rightarrow 0 \mathrm{~K}$. Dilution with both lanthanum and yttrium in this compound, as well as in $\mathrm{NdMg}_{3}$, reduces the residual linewidth. In the case of $\mathrm{CeMg}$, however, dilution does not modify the residual width or increase it with yttrium. We believe the difference in behaviour between the two systems is due to the different origins of the low temperature relaxation mechanisms. It appears that the residual width in $\mathrm{CeMg}_{3}$ is mainly due to the exchange interactions since dilution reduces the width, whereas in $\mathrm{CeMg}$ the origin of the residual width is the Kondo coupling between local moment and conduction electrons. This is consistent with the fact that magnetic properties of $\mathrm{CeMg}$ are similar to those of the Kondo compound $\mathrm{CeAl}_{2}$ as for example in the pressure dependence of $T_{\mathrm{N}}$. 


\section{References}

[1] Coqbuin, B., in Magnetism of Metals and Alloys, M. Cyrot, Ed. (North Holland) 1982, p. 295.

[2] Lawrence, J. M., Reiseborough, T. F. and Parks, R. D., Rep. Prog. Phys. 44 (1981) 1.

[3] Holland-Moritz, E., Loewenhaupt, M., Schmatz, W. and Wohlleben, D. K., Phys. Rev. Lett. 38 (1977) 983.

[4] Loewenhaupt, M. and Holland-Moritz, E., J. Magn. Magn. Mat. 14 (1979) 227.

[5] Holland-Moritz, E., Wohlleben, D. and LoewenHaUPt, M., Phys. Rev. B 25 (1982) 7482.

[6] Murani, A. P., Phys. Rev. B 28 (1983) 2308 ; J. Phys. C 33 (1983) 6359.

[7] Steglich, F., Bredl, C. D., Loewenhaupt, M. and Schotte, D. K., J. Physique Colloq. 40 (1979) C5-301.

[8] Murani, A. P., Knorr, K., Buschow, K. H. J., Benoît, A. and Flouquet, J., Solid State Commun. 36 (1980) 523.

[9] Pierre, J., Murani, A. P. and Galera, R. M., J. Phys. F 11 (1981) 679.

[10] Pierre, J. and Murani, A. P., Crystal electric fields and structural effects in f-electron systems, Ed. Crow, Guertin and Mihalisin (Plenum Press, New York) 1980, p. 607.

[11] Pierre, J., Galera, R. M. and Siaud, E., submitted to J. Physique.
[12] Galera, R. M., Murani, A. P. and Pierre, J., J. Magn. Magn. Mat. 23 (1981) 317.

[13] BeCker, K. W., Fulde, P. and Keller, J., Z. Physik B 28 (1977) 9.

[14] Lopes, L. C. and CoQBlin, B., Intern. Conf. on Valence fluctuations, 1984.

[15] Galera, R. M., Pierre, J. and Murani, A. P., Proc. of the Intern. Conf. on Valence instabilities, P. Wachter and H. Boppart (North-Holland Publishing Co) 1982, p. 519.

[16] Galera, R. M., Pierre, J. and Voiron, J., Solid State Commun. 46, 1 (1983) 45.

[17] Barbara, B., Cyrot, M., Lacroix, C. and Rossignol, M. F., J. Physique Colloq. 40 (1979) C5-340.

[18] DoniaCH, S., Valences instabilities and related narrowband phenomena, Ed. R. D. Parks (Plenum Press, New York) 1977, p. 169.

[19] Lavagna, M., LacroiX, C. and Cyrot, M., Phys. Lett. 90A (1982) 210.

[20] Steglich, F. and Loewenhaupt, M., Proc. of the Intern. Conf. on Valence instabilities and related narrow band phenomena, Ed. R. D. Parks (Plenum Press) 1977, p. 467.

[21] Frick, B., Loewenhaupt, M., Debray, D., Just, W., Z. Physik B 51 (1983) 223. 